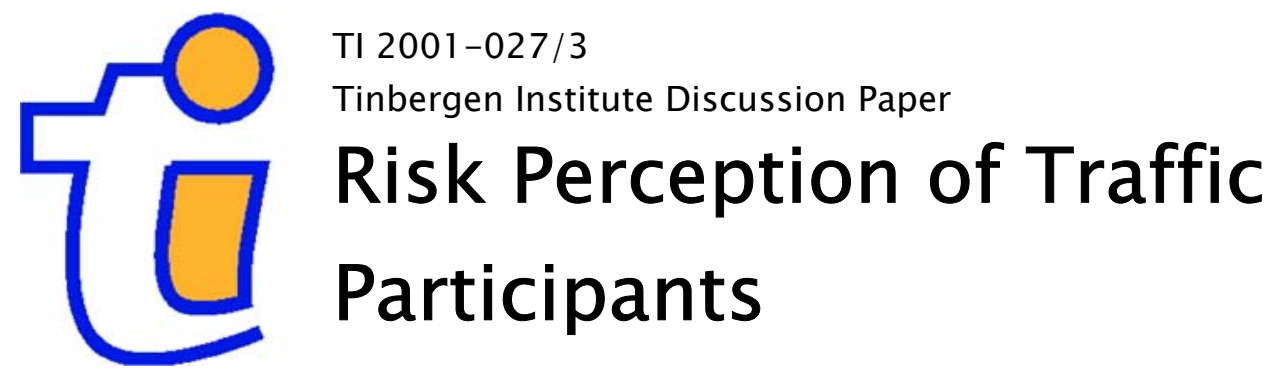

Arianne de Blaeij
Daniel van Vuuren

Published in Accident Analysis and Prevention 35(2): 167-175. 
Tinbergen Institute

The Tinbergen Institute is the institute for economic research of the Erasmus Universiteit Rotterdam, Universiteit van Amsterdam, and Vrije Universiteit Amsterdam.

Tinbergen Institute Amsterdam

Roetersstraat 31

1018 WB Amsterdam

The Netherlands

Tel.: $\quad+31(0) 205513500$

Fax: $\quad+31(0) 205513555$

Tinbergen Institute Rotterdam

Burg. Oudlaan 50

3062 PA Amsterdam

The Netherlands

Tel.: $\quad+31(0) 104088900$

Fax: $\quad+31(0) 104089031$

Please send questions and/or remarks of nonscientific nature to wdriessen@few.eur.nl.

Most TI discussion papers can be downloaded at http://www.tinbergen.nl. 


\title{
Risk perception of traffic participants
}

\author{
ARIANNE DE BLAEIJ and DANIEL VAN VUUREN \\ Vrije Universiteit \\ Department of Spatial Economics \\ De Boelelaan 1105 \\ 1081 HV Amsterdam \\ email: blaeij@econ.vu.nl, dvuuren@tinbergen.nl
}

\begin{abstract}
In this paper we study the risk perception of traffic participants. Firstly, we give an overview of previously used methodologies for the monetary valuation of transport safety. These methodologies do not distinguish between the individual's assessment of probabilities and her valuation of possible outcomes. A great disadvantage of these approaches is therefore that one has to make the assumption that people correctly perceive the probabilities. Prospect theory does not make this assumption. Our procedure, which is based on this methodology, consists of three steps. The first step is to determine the certainty equivalent for avoiding road accidents. The second step is the elicitation of the utility function. The final step is the elicitation of the probability weighting function. With this information we directly obtain the perceived value of the probability for accident $A_{i}$.

The first, tentative, results show that the valuation of losses is well represented by a utility function that is concave in shape. Secondly, our preliminary results show that when people have to choose whether or not to participate in a potentially risky activity with a low probability of the "bad outcome" (say $\leq 1 / 100$ ), they base their decision on the possible outcomes of the activity rather than on the probabilities involved. The empirical conclusion is therefore that people base their final decision mainly on the possible outcomes and not so much on probabilities whenever there are very small probabilities involved.
\end{abstract}




\section{Introduction}

This paper studies the risk perception of traffic participants, making use of prospect theory. Although there has been published quite some theoretical literature in this field (Kahneman and Tversky (1979) is a standard reference), it seems that the application of prospect theory is relatively unexplored in the field of transport economics; we did not mention any application of this methodology. This may be seen as quite remarkable, as studies in the area of transport economics typically involve individuals that have to face risky choices.

One may not only think about the topic of this paper, the risk of being victim to a traffic accident, but also about missing a connection of a public transport chain (Rietveld et al., 2001), the risk that one does not have a seat in a train, the risk that one cannot find a parking spot, the risk of facing congestion, etc. (Peeters et al., 1998). The first paper consists of three parts: (i) the unreliability in public transport chains is determined from actual arrival and departure data, (ii) the individual's perception of unreliability is determined through a stated preference survey and (iii) policies which improve the reliability of public transport chains are tested, while the individual's perception is taken into account. However, both studies do not distinguish between the individual's perception of probabilities and the utility of the possible outcomes (such as "arrival on time", "10 minutes delay", etc.). Instead, the authors do not make any assumptions about the individual's decision framework to conclude - amongst others - that the average traveler has a much higher valuation of travel time when more risk is involved, thereby implying risk aversion. Rietveld et al. (2001) find that that a certain additional minute of travel time is valued at 27 cents, whereas the valuation of a $50 \%$ probability of a 2 minute delay is 64 cents

To give some examples from other areas than transport economics, we want to mention two papers that involve the study of the individual's risk perception of so-called potentially risky activities. The resemblance between these studies and the current paper is their focus on activities involving a small risk, but huge consequences if the outcome is 'bad'. Morris et al. (1994) make use of straightforward statistical analyses in order to study the risk perception of alcohol use during pregnancy. As Dowling (1986) has argued that risk perception for a large part depends on the particular product that is evaluated, the authors have preferred to concentrate on a single activity instead of analysing more generalised risk perception measures. The central purpose of their research is to identify the perceptual dimensions that distinguish between (i) drinkers, (ii) non-drinkers and (iii) pregnant abstainers. The results of this paper may look somewhat surprising. For example the study indicates that high income, white and also highly educated pregnant women are more likely to consume alcoholic beverages during their pregnancy. Concerning risk perception, drinkers attributed less risk to "a small number of drinks on a few occurrences" than did others. On the other hand they attributed more risk to "a large number of drinks on many occasions" than the other women did.

Liu and Hsieh (1995) adopt the approach that has been developed by Viscusi $(1990,1991)$ to examine whether individuals underestimate smoking risk and whether individuals are taking the risks into account when they make their smoking decisions. In their paper the determinants of risk perception are established within a Bayesian learning framework, 
distinguishing between (i) prior belief, (ii) individual experience and (iii) public information. The authors conclude that young, educated and nonsmoking people, as well as people that have read warning signs, have a higher risk assessment than average. More generally, they conclude that the risk perceptions of cigarette smoking are substantially overestimated, but that individuals actually do make rational responses to those perceived risks. As possible explanations for this high perception of smoking risks, the authors conclude that (i) the Bayesian learning framework predicts that individuals will overestimate the risks of highly publicised events, and (ii) public information usually informs about the existence of a risk but not about its the magnitude.

Hence it can be seen that many approaches are possible to analyse the decision process of individuals who have to make risky choices. In section 2 we give an overview of methodologies that have been previously applied to the case that is also studied in this paper, i.e. the monetary valuation of transport safety. As said, these approaches do not distinguish between the individual's assessment of probabilities and her valuation of possible outcomes, but adopt an unified framework of which the expected utility framework is of course the most prominent. In section 3 some key statistics about transport safety in the Netherlands are presented. These figures have also been used in the questionnaire that has been set up for the purpose of this paper. Section 4 discusses our research approach and contrasts it with the previous methodologies of section 2 . The empirical results are discussed in section 5, and section 6 concludes this paper.

\section{Previously applied methodologies in the field of transport safety}

For policy decisions it is important to have a monetary value of fatal and non-fatal road injuries. Crucial components of the valuation of a road injury are the severity and the risk of the accident. Because a change in risk of an accident is valued and not the accident itself, the measure at stake is the value of a statistical life (VOSL) or value of a statistical injury instead of value of life (VOL) or value of an injury.

Among economists the widespread opinion is that the monetary value of fatal and nonfatal road injuries should reflect preferences of individuals. Many methods have been used for estimation of the utility function and determination of the monetary value (WTP). These methods can be divided into two groups, which have been named A and B in Table 1. This section briefly describes the methods that are mentioned in this table. This makes it possible to see how prospect theory can add to the existing literature and if it can make a contribution to improve estimations of the value of a statistical life.

Table 1. Utility measurement methods

Methods used to estimate the utility (and value) of (statistical road) injuries:

\begin{tabular}{ll}
\hline A. Revealed preference methodology & B. Stated preference methodology: \\
& - Contingent valuation \\
& - Conjoint analysis, choice experiments \\
& - Standard gamble, certainty equivalent \\
& - Trade-off methods
\end{tabular}




\subsection{Methodologies}

\subsubsection{Revealed Preference}

In revealed preference studies it is assumed that all road users are rational and informed. This assumption implies that the road users know the objective risk levels and that they act according to the respective probabilities. The objective probability to become involved in an accident with serious injuries is small. Revealed preference studies measure the utility of changes in these small probabilities and the willingness to pay (WTP) by looking at revealed behaviour (e.g. buying/ wearing seat belts, choosing a particular speed (e.g. Jondrow et al., 1983)). A problem with the valuation of a risk decline in road safety is that most market behaviour decisions are not explicitly made, because seat belts are compulsory, airbags and ABS are standard accessories, etc. If these decisions were explicitly made there would still be another problem; namely that individuals take into account their perceived risk level (instead of the objective risk level) when making their decisions. If a reliable probability weighting function becomes available, revealed preference methodology will improve significantly.

\subsubsection{Contingent Valuation}

CVM directly asks the respondents the true WTP (WTA) for a risk reduction. The WTP represents the economic value of the risk decline. This solves the first problem mentioned in the RP part; by using CVM the researcher knows for sure that the (hypothetical buying) decision is explicitly made. It is assumed that the values elicited with CVM will correspond with those that would emerge on the real market. For the CVM method the objective risk level must be valued. Here, the same problem occurs as mentioned in the description of the RP method, that respondents base their decisions on their perceived, instead of the real, risk level. A question in the road safety context can be how much money a person is willing to pay to obtain a reduction in the risk of an accident. In CVM road safety valuation studies it is assumed that the perceived risk level equals the risk level given in the question or the risk level mentioned by the respondent. The CVM has been used in environmental economics for valuing natural parks, wetlands, etc, for about 30 years (Hoevenagel, 1994).

\subsubsection{Conjoint analysis}

In economics the conjoint analysis (CA) or choice experience method is seen as an extension or variant of contingent valuation to value changes in environmental commodities (Adamovics et al., 1998). Apart from this, this research method has been used for 20 years in marketing research to evaluate consumer acceptance of multiattribute commodities. CA is a generalisation of CVM in the sense that rather than asking people their WTP for a risk reduction, the respondents are asked to make repeated choices between bundles of attributes (Adamovics et al., 1998). For valuation of a statistical life at least two attributes are needed, one attribute with money amounts and one with risk levels. In dichotomous CV questions the bundle of attributes consists of these two attributes. (The respondents make a choice between a high-risk level or a lower 
risk level and paying an amount of money.) In CA road safety valuation studies it is assumed that the respondents are able to gauge the given risk levels.

Most of the CA applications in economics are in environmental economics. Until now CA road safety valuation studies have not been carried out. A possible question in the road safety context would be to make a choice between the following possibilities: i) A road with a speed limit of 80 kilometers per hour, an accident risk of 6 in 100,000 road kilometers and a fee of 5 guilders if you want to use the road. ii) A road with a speed limit of 60 kilometers per hour, an accident risk of 4 in 100,000 road kilometers and a fee of 5 guilders if you want to use the road. iii) A road with a speed limit of 60 kilometers per hour, an accident risk of 5 in 100,000 road kilometers and a fee of 2,50 guilders if you want to use the road.

\subsubsection{Standard Gamble (Certainty Equivalence Method)}

The standard gamble method is developed in health economics and taken over in transport economics as an alternative method to CVM to value the economic value and utility of safety. The standard gamble method is a certainty equivalent method. This method requires respondents to fill in a sure outcome such that the individual is indifferent between this outcome and participating in a given lottery. Preferences of the individual are then explained by expected utility theory. A standard gamble question example is taken from Dolan et al., 1995. Suppose you were in a road accident and suffered the following injuries (are made explicit for the respondents). You are told by the hospital that a special treatment is available which, upon success, puts your injuries in a better, specified condition. However, there is a chance that the treatment fails and if so, you will die. The respondents have to decide whether to have the treatment or not at different risk levels. Valuing a statistical life in this way can solve the problem of different perceptions of small probabilities. A disadvantage of this method is that the valuation situation has changed. It is supposed that the respondent was already involved in an accident. This means that what one is valuing is another situation, so another "good" than the safety improvement is being valued with $\mathrm{CV}$ and CA.

\subsubsection{Trade-off method}

The trade-off method is developed as an alternative for the standard gamble method. The trade-off method is also based on expected utility theory. This method requires two lotteries such that the individual is indifferent between participating in one of the two lotteries. In this method, respondents trade off utilities (amounts of money, time) with the same probability levels in the two lotteries or the respondents trade off probability levels (risk levels) with different, but fixed utility levels in the two lotteries. An example of the risk-risk trade-off method can be found in Viscusi et al., 1991 and in comparison with the standard gamble approach in Dolan et al., 1995. The example question is taken from Dolan (1995). Suppose a particular road safety feature would reduce your risk of a particular injury $(\mathrm{K})$ but only by increasing your risk on another injury $(\mathrm{R})$ by 60 in a million. I'd like to know how much you would want your risk of $\mathrm{K}$ to be reduced to make up for increasing your risk of $\mathrm{R}$ by 60 in a million. 


\subsection{Discussion and comparison of methodologies}

For about 30 years, research has been done to estimate the negative value of fatal and non-fatal accidents. The result is that methodologies are improved and that new methodologies have been developed. In paragraph 2.1 five methodologies have been described. In this paragraph the methodologies are compared making use of road safety valuation literature.

An article that compares the revealed preference and contingent valuation method is Lanoie et al., 1995. Lanoie et al., 1995 systematically compare the values of a statistical life obtained from the RP methodology and from CVM applied to the same individuals. From a theoretical point of view the two methods should not provide the same results because the RP approach estimates a local trade-off and the CV approach estimates a movement along a constant expected utility locus. The RP estimate is based on factual questions for the wage-risk study and the CV method is based on hypothetical questions about job safety. The CV answers can be compared with the RP answers. Compared with other literature both value estimates are very high. This may be due to the fact that it is difficult for people to deal with events with very small probabilities. Another explanation is that road users only take into account the severity of a possible accidents and not the risk on an accident when they value a road injury. This explanation is one of our main conclusions.

The RP values from the different specifications are within the 5\% confidence interval of the WTP value. When using the non-parametric "bootstrap" method for estimating the distribution of a statistic that compares both methods, it indicates that the differences are not concentrated around zero and that the results are very unstable. Risk aversion of the respondents can be an explanation for the large differences in estimation result between RP and CVM. Risk averse people are working in jobs where the existence of an explicit job premium is unlikely. This means that the only way to obtain their valuation is through a questionnaire.

Articles that use both the contingent valuation method and the standard gamble approach, are Jones-Lee et al. (1995b) and Jones-Lee et al. (1995a). Carthy et al. (1999) did an empirical study for which they use a multi-stage approach. They use both the CVM and SG method.

The study of Jones-Lee et al. (1995b) make use of the contingent valuation questions and of the standard gamble questions to elicit peoples preferences (DoT study). The goal was to estimate people's preferences for reducing their risks of various non-fatal road injuries relative to their preferences for reducing their risk of death in a road accident. In this paper the SG approach estimates the ratio of the marginal rate of substitution (MRS) of a category injury divided by the MRS of immediate death. The CV method estimates distinct marginal rates of substitution. So the estimation results of both methods are the ratios. Under the assumption that people behave like von Neumann-Morgenstern expected utility maximisers both methods should give the same ratio estimates for preventing a "typical" non-fatal injury. In this experiment the CVM produced a three times higher estimate. The potential causes for these differences are that individuals weight losses and gains different (prospect theory) and systematical biases in responses. 
These biases may be due to the respondents' unawareness of different magnitudes of risk reduction ${ }^{1}$. The authors of this paper have good reasons to expect that CV-estimates are upward biased and they could not detect any bias in SG estimates. They can only speculate about the systematical difference in response between the two response modes. The study of Jones-Lee et al. (1995a) is based on the same DoT study as Jones-Lee (1995b). They also make use of the contingent valuation questions and of the standard gamble questions to elicit the ratios (people's preferences). The CV estimates of the ratios are greater then the SG estimates. The study formulated various assumptions and conjectures that provide a (partial) explanation of the substantial differences between the ratio estimates. These hypotheses are not thoroughly tested. One of the hypotheses is that a pattern of non-expected utility is consistent with these disparities. The preferred explanation of the authors is the explanation of the existence of systematic biases. Respondents do not take the objective amount of risk reduction into account. The function that relates WTP to the size of variation in risk suggests a very high degree of local non-linearity. They conclude that advantages of SG in relation to CV are that: SG responses appear to be more sensitive to differences in injury severity. Respondents might expect to encounter such a situation in their own lives. It is natural to think only in terms of your own risk, and risk can be expressed on a smaller, better understandable, risk level. Respondents do not have to value a risk change in an initial very small risk level. In SG the probability levels are more manageable. SG questions involve no reference level.

Carthy et al. (1999) estimate a WTP based VOSL for road risks by using a multi-stage approach which involves "chaining together" responses to contingent valuation and standard gamble questions. In order to help respondents to arrive at an appropriate tradeoff between money and the risk of death, it may be necessary to break the task down into a number of simpler and more manageable steps: 1) CV question for WTP/WTA for cure for a given non-fatal road injury. 2) Elicit the broad order of magnitude of the respondents MRS (Marginal Rate of Substitution). 3) (Modified) SG question to estimate the respondents MRS of wealth for risks of death a result of a road accident. 4) Step 2 and 3 are chained to get the implicit MRS of wealth for risk of death as a result of a road accident. In step 3 the max. EU approach is used to measure the change in probability. Two different treatments are used in this research. The objective is to find the probability level of the second treatment (the probability level of the first treatment is given) at which the respondent is indifferent between the two treatments. The modified SG is used, because otherwise it is very difficult for the respondents to handle with small risks in case of medical treatment. The respondents found this method manageable. This and other reasons make that the authors believe that VOSL estimates estimated in this way form a sounder basis for policy conclusions.

An advantage of conjoint analysis compared with the contingent valuation method is that CA allows the researcher to "value" attributes as well as situational changes (this is also possible with CVM, but then a large amount of questions is needed). Another advantage is that CA makes it possible to measure compensation in other goods instead of in money (Adamovics et al., 1998).

\footnotetext{
${ }^{1}$ Jones-Lee et al. (1993)
} 
Articles that compare the standard gamble approach and the trade-off approach are Viscusi (1991), Dolan et al. (1996) and Dolan et al. (1995). Dolan et al. (1996) compare a time-trade off with a standard gamble. In the time trade-off the respondents do not have to take into account a risk level. This trade-off can also be seen as a choice between two bundles of attributes, as a conjoint analysis.

It is easier for respondents to make risk-risk trade-offs then risk-money trade-offs for important reasons. The RR method adapts to whether respondents understand their valuation task (an advantage in comparison with the money trade-off is that no binding budget constraint exist). Because the method produces values for morbidity risk reduction in terms of trade-offs with another risk measure, the respondents are not influenced by the respondents' attitudes towards risk per se. A disadvantage is that for translation of the utility measure into money values, a risk-money trade-off is still necessary. This can be done by using VOSL estimates of published literature or by using survey results (Viscusi, 1991).

Dolan et al. (1996) compare the time-trade-off (TTO) and the standard gamble (SG) procedure for measuring utility for two situations, questionnaires with and without supporting objects. Both methods make restrictive assumptions about individual preferences, in such a way that they can not reasonably act as perfect proxies for utility. This means that it is unknown which method is preferable. In the TTO health improvements are valued in terms of the amount of life expectancy an individual is prepared to sacrifice, by assuming that utility is a positive function of longevity. In this paper the TTO is a choice between two alternatives that have outcomes that are known with certainty.

Dolan et al. (1995) test the viability of and compare the risk-risk (RR) and the standard gamble ( $\mathrm{SG}$ ) procedures for measuring utility. If the respondents maximise expected utility, the RR method yield the same preferences as the SG procedure, nevertheless this article gives two reasons why the two methods may produce different results. The first reason is that people do not behave as expected utility maximisers. The extent of this failure is unknown. The second reason is that one method may be easier for respondents to deal with. SG questions express changes as out of hundred, RR trade express the risk level less imaginable, as changes in a million. But the RR-questions involved more realistic probabilities then the SG questions.

The results indicate comparable mean and median visual-analogue-scale (VAS) scores of the key health states retrieved with the RR and SG questions. Another result indicates that the utility indices estimated via the SG are higher than those estimated via RR for every level of injury. This can be seen as evidence for non-expected utility theory and this result could be consistent with prospect theory. Other possible explanations for the different observations are the status quo effect and simple confusion. The conclusion of this paper is that the RR question is the preferred question in many health state questions, because it estimates utility levels for realistic probabilities. The SG questions however, are much more manageable then the RR questions. 


\section{Facts about accident probabilities}

The number of deaths due to a traffic accident is low compared with the total number of deaths. Less then 1 out of 100 "total" deaths is due to a traffic accident. The situation is somewhat different for the age category between 5 and 25. In this category 1 on 3 deaths is due to a traffic accident. For this category the most important cause of death is a traffic accident. The government has some reasons for policy intervention to decrease the transport unsafety. First of all, as already seen, transport unsafety is a public health problem. Moreover, it declines the economic prosperity and it declines social well being In the "Meerjarenplan Verkeersveiligheid" (a transport safety plan) objectives for 2010 are set. In 2010 the amount of fatal accidents should have declined with $50 \%$ and the amount of injuries by $40 \%$ compared with the base year 1986. The objectives are in absolute terms, so independent of the increase in mobility. If the increase in mobility is taken into account this means that the risk on death should decline with 5.5\% and the risk on an injury with 4\% per year (Koornstra et al., 1990).

Different characteristics are the cause of the accident risk-levels that are faced by individuals. Examples are personal characteristics such as age, physical and mental health, infrastructure characteristics, transport intensity on the roads, the weather and means of transport characteristics. In our research we just take into account the seriousness of the accident and the different means of transport. Accident probability is defined here as the ratio between the amount of injuries and the amount of travelled kilometres. This probability can be calculated for all mobility in the Netherlands, but also for the different transport segments such as cyclists, children, etc. (Koornstra et al., 1990).

We use accident probabilities at three injury levels. In Table 2 these probabilities on accidents with different injury levels are given for 1997. The probabilities are transformed in probability on a particular accident per 20,000 kilometres. This average figure of 20,000 kilometres per annum is also used in the questionnaire that has been used for the purpose of this paper. It is easier for respondents to interpret the smaller risk level per 20,000 kilometres than per 10,000,000,000 kilometres. We choose 20,000 kilometres because this is a usual amount of kilometres a car driver drives per year in the Netherlands ${ }^{2}$. In Table 3 probabilities on accidents with different means of transport are given, also for 1997.

Table 2. Accident probabilities (Sources: CBS(1998) and SWOV (1998))

\begin{tabular}{cccc}
\hline & per $10^{9}$ travel & per 20,000 travel \\
$\mathrm{kms}$ & $\mathrm{kms}$ & $\begin{array}{c}\text { Figures used in } \\
\text { survey }\end{array}$ \\
\hline fatal / fatally wounded & 6.5 & $1: 7657$ & $1: 7500$ \\
Heavily wounded & 107.5 & $1: 465$ & $1: 500$ \\
Lightly wounded & 504.7 & $1: 99$ & $1: 100$ \\
\hline
\end{tabular}

\footnotetext{
${ }^{2}$ Which implies that for most people the situation as sketched in the questionnaire is more intuitively appealing
} 
Table 3. Probabilities for fatal accidents, given means of transport (Sources: CBS(1998) and SWOV (1998))

\begin{tabular}{cccc}
\hline & per $10^{9}$ travel & per 20,000 travel & figures used in \\
$\mathrm{kms}$ & $\mathrm{kms}$ & survey \\
\hline motorcycle & 56.3 & $1: 889$ & $1: 900$ \\
bicycle & 20.1 & $1: 2490$ & $1: 2500$ \\
car & 4.5 & $1: 11161$ & $1: 11000$ \\
bus & 0.1 & $1: 625000$ & $1: 625000$ \\
\hline
\end{tabular}

\section{Outline of research approach}

A great disadvantage of the approaches that were sketched in the previous section is that one has to make the assumption that people correctly perceive the probabilities involved. In this section we propose the methodology, previously termed prospect theory, that does not make this assumption a priori. Instead, it is possible to distinguish between the perception of probabilities and the perception of outcomes. It is still assumed that those perceptions are independent of one another. In other words, prospect theory assumes that the perception of a probability is independent of the outcome to which the probability corresponds (and vice versa). Our procedure consists of three steps:

1. Determination of the certainty equivalent in order to avoid road accidents

2. Elicitation of the utility function

3. Elicitation of the probability weighting function

After carrying out these steps we will have obtained the following:

a. The valuation of road accidents in terms of money

b. The valuation of money losses in terms of utility

c. The valuation of road accidents in terms of utility

d. The perception of small probabilities with respect to road accidents

Of course, the focus of this paper is on a,c and d. However interesting, the results in $b$ are regarded as a by-product of this paper.

\section{Determination of the willingness to pay in order to avoid road accidents}

The respondents are asked to give their certainty equivalent (CE) for the lottery (p,A; 1$\mathrm{p}, 0)$. In these lotteries the accident $\mathrm{A}$ is fixed and the amount of money $\mathbf{x}$ is iterated according to a bisection rule. After each iteration the WTP value of the respondent is further approached by $\mathbf{x}$. Note that we could have been asking for the WTP value directly, but it has been argued by Abdellaoui (1998) that this would yield results that are less consistent than the results of the current approach. In the questionnaire each lottery is repeated 6 times, thereby adjusting $\mathbf{x}$ according to the bisection rule. In case the final value of $\mathbf{x}$ seems to deviate still from the WTP value of the respondent, we directly asked the respondent about his/her WTP. 
This sequence of 6 lotteries has been repeated 3 times. Once for every type of accident:

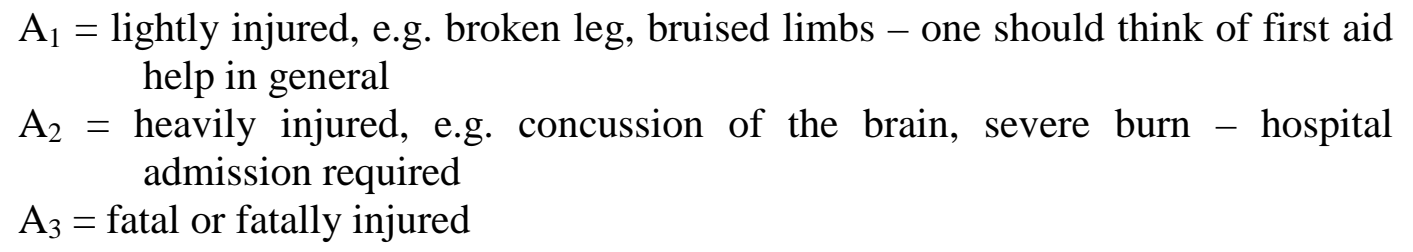

To make the questions as realistic as possible we use the realistic probabilities given in Table 2 and 3.

The starting values of $\mathrm{x}$ were set at the following (maximum) levels for each accident:

$$
\begin{aligned}
& x_{10}=f 1,000 .^{3} \\
& x_{20}=f 10,000 .- \\
& x_{30}=f 20,000 .-
\end{aligned}
$$

\section{Elicitation of the utility function}

At this stage we estimate the utility function in terms of money. It should be stressed that we only estimate the negative part of the utility function, so the results only apply to losses.

The data for the elicitation of the utility function will be obtained in the same way as in Abdellaoui (1998) and Bleichrodt and Pinto (1998). It starts by constructing a standard sequence of negative outcomes, which means that our questions aim at obtaining a sequence of monetary values $\mathrm{x}_{0}, \mathrm{x}_{1}, \mathrm{x}_{2}, \ldots$, such that $\mathrm{U}\left(\mathrm{x}_{1}\right)-\mathrm{U}\left(\mathrm{x}_{0}\right)=\mathrm{U}\left(\mathrm{x}_{2}\right)-\mathrm{U}\left(\mathrm{x}_{1}\right)=\ldots$ Together with two normalising conditions it is then possible to construct a utility function.

The first lottery takes the form $\left(\mathrm{p}, 0 ; 1-\mathrm{p}, \mathrm{x}_{0}\right) \sim\left(\mathrm{p},-10 ; 1-\mathrm{p}, \mathrm{x}_{\mathrm{I}}\right)$, where $\mathrm{x}_{0}$ is provided and respondents are asked to fill in $\mathrm{x}_{1}$. After obtaining $\mathrm{x}_{1}$, the respondents are asked to fill in $\mathrm{x}_{2}$ in the lottery $\left(\mathrm{p}, 0 ; 1-\mathrm{p}, \mathrm{x}_{1}\right) \sim\left(\mathrm{p},-10 ; 1-\mathrm{p}, \mathrm{x}_{2}\right)$, etc. which yields the standard sequence $\mathrm{x}_{0}$, $\mathrm{x}_{1}, \mathrm{x}_{2}, \ldots$ Note that in this step we did not choose to obtain the $\mathrm{x}_{\mathrm{i}}$ 's according to a bisection rule. The reason for this is mainly practical, as we did not want to burden our respondents with too many questions. Secondly, we assumed that after the first part of the questionnaire, respondents would have obtained some intuition for how to correctly estimate a trade-off value. In the questionnaire we obtain two standard sequences of length 4. The first has an initial value of -Dfl 100,000.- and the second has an initial value of -Dfl 2,000.- We have decided to add a second standard sequence as a kind of insurance for the case that the first sequence does not give enough information. It could be possible for example that the first sequence is only very slowly increasing, which means that we would not have enough information about the utility of relatively small losses.

\footnotetext{
${ }^{3}$ The symbol $f$ is the symbol for the Dutch guilder. One guilder, $f 1,-$, equals about 0.45 Euro or $£ 0.27$.
} 


\section{Elicitation of the probability weighting function}

The lotteries are of the form: $(\mathrm{p}, \mathrm{A} ; 1-\mathrm{p}, 0) \sim(\mathrm{p}, \mathrm{y} ; 1-\mathrm{p}, \mathbf{x})$. The monetary value $\mathrm{y}$ is given in advance, as are the probabilities $\mathrm{p}$ and the accident A. Again the respondents have to fill in $\mathbf{x}$ directly; because of the practical reasons that we have mentioned earlier it would be too time-consuming to obtain $\mathbf{x}$ according to the iteration procedure.

Let $x_{i}$ be respondent's (approximated) indifference value corresponding to accident $A_{i}$. This yields the equations

$$
\mathrm{w}\left(\mathrm{p}_{\mathrm{i}}\right) \mathrm{U}\left(\mathrm{A}_{\mathrm{i}}\right)+\left(1-\mathrm{w}\left(\mathrm{p}_{\mathrm{i}}\right)\right) \mathrm{U}(0)=\mathrm{w}\left(\mathrm{p}_{\mathrm{i}}\right) \mathrm{U}\left(\mathrm{y}_{\mathrm{i}}\right)+\left(1-\mathrm{w}\left(\mathrm{p}_{\mathrm{i}}\right)\right) \mathrm{U}\left(\mathrm{x}_{\mathrm{i}}\right) \quad \mathrm{i}=1,2,3
$$

Rewriting this expression yields

$$
\mathrm{w}\left(\mathrm{p}_{\mathrm{i}}\right)=\left[\mathrm{U}(0)-\mathrm{U}\left(\mathrm{x}_{\mathrm{i}}\right)\right] /\left[\mathrm{U}\left(\mathrm{y}_{\mathrm{i}}\right)-\mathrm{U}\left(\mathrm{A}_{\mathrm{i}}\right)-\mathrm{U}\left(\mathrm{x}_{\mathrm{i}}\right)+\mathrm{U}(0)\right] .
$$

However, in step 1 we have obtained the certainty equivalent for the lotteries $\left(\mathrm{p}, \mathrm{A}_{\mathrm{i}} ; 1\right.$ $\mathrm{p}, 0)$. Denoting the utility value of this certainty equivalent by $\mathrm{U}\left(\mathrm{CE}_{\mathrm{i}}\right)$, this equation rewrites as

$$
\mathrm{w}\left(\mathrm{p}_{\mathrm{i}}\right)=\left[\mathrm{U}\left(\mathrm{CE}_{\mathrm{i}}\right)-\mathrm{U}\left(\mathrm{x}_{\mathrm{i}}\right)\right] /\left[\mathrm{U}\left(\mathrm{y}_{\mathrm{i}}\right)-\mathrm{U}\left(\mathrm{x}_{\mathrm{i}}\right)\right] .
$$

As all the expressions on the right hand side are known from the previous steps, we thus obtain directly the perception value of the probability, which belongs to accident $A_{i}$.

The values for $y_{i}$ have been fixed at

$$
\begin{aligned}
& y_{1}=-f 100 \\
& y_{2}=-f 1000 \\
& y_{3}=-f 10,000
\end{aligned}
$$

respectively.

\section{Estimation and results}

We have obtained our data by handing out a questionnaire among university personnel. Many respondents turned out to have difficulties with providing answers to the different questions, and hence we got back 17 out of the 33 distributed questionnaires.

Note that in the following absolute values are reported; only losses are considered, so all amounts are negative. The different types of accidents are denoted as follows:

$\mathrm{LI}=$ lightly injured

$\mathrm{HI}=$ heavily injured

$\mathrm{F}=$ fatally wounded / fatal 
Table 4 contains some characteristics of the outcomes of the first part of the survey. The average respondent indicated that, in order to avoid a (yearly) probability of 0.01 on an accident with light injury, he was willing to pay an amount of Dfl 314. The average WTP values for a 1/500 yearly probability on heavy injury and 1/7500 probability for fatal injury were equal to Dfl 5,549 and Dfl 10,549 respectively. However, as indicated by the significant skewness to the right, the empirical distributions of the valuation showed quite some relatively high values. The table therefore also includes statistics which are less sensitive to outliers, such as the median, the geometric mean and the harmonic mean ${ }^{4}$. The median values are equal to Dfl 156, Dfl 963 and Dfl 5,000 respectively, which in an expected utility framework would imply a (yearly) valuation of Dfl 15,625, Dfl 481,250 and Dfl 37,500,000 for avoiding with certainty light injury, heavy injury and fatal injury. The high standard deviations indicate that there is much variation among the respondents' valuation of the different types of accidents. The variation coefficients show that the relative variation becomes larger as the severity of the accident increases. In other words, the individual perception not only becomes larger in an absolute sense, but also in a relative sense, when more severe accidents are concerned.

For the estimation of the utility function we have chosen the Box-Cox specification. More sophisticated specifications are quite difficult to estimate as we had only a limited amount of observations. Easier specifications, such as the linear specification turned out to have a likelihood which was extremely low as compared to the reported likelihoods in Table 5. Therefore we only report the estimations of this specification, which is given by

$$
\mathrm{U}(\mathrm{x})=-\left(\mathrm{x}^{\alpha}-1\right) / \alpha+\varepsilon
$$

Table 4. Characteristics of the WTP data

\begin{tabular}{|c|c|c|c|c|c|c|}
\hline & LI & HI & $\mathrm{F}$ & $\mathrm{LI}^{5}$ & $\mathrm{HI}^{5}$ & $\mathrm{~F}^{5}$ \\
\hline $\begin{array}{l}\text { Associated } \\
\text { probability }\end{array}$ & $1: 100$ & $1: 500$ & $1: 7500$ & 1 & 1 & 1 \\
\hline Average & 314 & 5549 & 10549 & 31,356 & $2,774,647$ & $79,113,971$ \\
\hline Median & 156 & 963 & 5000 & 15,625 & 481,250 & $37,500,000$ \\
\hline Geometric Mean & 131 & 1690 & 3032 & 13,029 & 844,950 & $22,740,324$ \\
\hline Harmonic Mean & 42 & 466 & 571 & 4247 & 232,764 & $4,282,839$ \\
\hline Standard deviation & 434 & 7344 & 14658 & & & \\
\hline $\begin{array}{l}\text { Variation } \\
\text { coefficient }^{6}\end{array}$ & 1.383 & 1.323 & 1.390 & & & \\
\hline Skewness & 2.771 & 1.677 & 1.846 & & & \\
\hline
\end{tabular}

\footnotetext{
${ }^{4}$ The logarithm of the geometric mean is equal to the average of logarithms, and the inverse of the harmonic mean is equal to the average of the inverses. It can be easily shown that: harmonic mean < geometric mean < arithmetic mean.

${ }^{5}$ Valuation of the accidents according to 'expected utility'.

${ }^{6}$ The variation coefficient equals the standard deviation devided by the mean.
} 
A familiar property of this specification is that $U$ tends to the logarithmic function as $\alpha$ approaches zero, and $U$ is equal to the linear specification if $\alpha$ equals one. Estimation of the model points out that $\alpha$ lies in the range $0.12-0.13$, dependent on which error distribution is chosen. This implies that the average subject exhibits a convex utility function for losses, a result that is in accordance with the findings of Fennema and van Assen (1999). These authors have estimated a power specification of the utility function ${ }^{7}$, and have found a parameter value which equals about 0.35 . Although this estimate is not directly comparable to our estimates for the Box-Cox specification, it is clear that our results indicate a more concave utility function. A possible explanation for this is that Fennema and van Assen use smaller money values than we did, implying that the (conditional) utility function for small losses is less concave than the (conditional) utility function for large losses, as can be clearly seen in Figure $1^{8}$. The likelihood scores that are reported below indicate that the model containing a double-exponential error term suits the data best.

Note that a possible improvement of the current model would be a stochastic $\alpha$; this would allow for preference heterogeneity among different persons. In a formula,

$$
\alpha_{i} \sim N(\alpha, \tau) .
$$

At present we have not estimated this model however, as we have had to restrict ourselves to other matters.

Table 5. Parameter estimates of the Box-Cox specification

\begin{tabular}{lccc}
\hline Distribution $\varepsilon$ & Normal Logistic & $\begin{array}{c}\text { Double } \\
\text { Exponential }\end{array}$ \\
\hline Mean log-likelihood & -1.542 & -1.775 & -1.439 \\
$\alpha$ & 0.131 & 0.133 & 0.120 \\
$\operatorname{var}(\varepsilon)$ & 2.111 & 1.173 & 1.635 \\
\hline
\end{tabular}

\footnotetext{
${ }^{7} \mathrm{U}(\mathrm{x})=-\mathrm{x}^{\alpha}$.

${ }^{8}$ Note that we have added the (positive) constant $\mathrm{U}(0)$ to our utility function and have rescaled the Fennema/van Assen utility function such that the begin- and endpoints coincide. This makes (visual) comparison of the two specifications easier.
} 
Figure 1. Estimated utility function

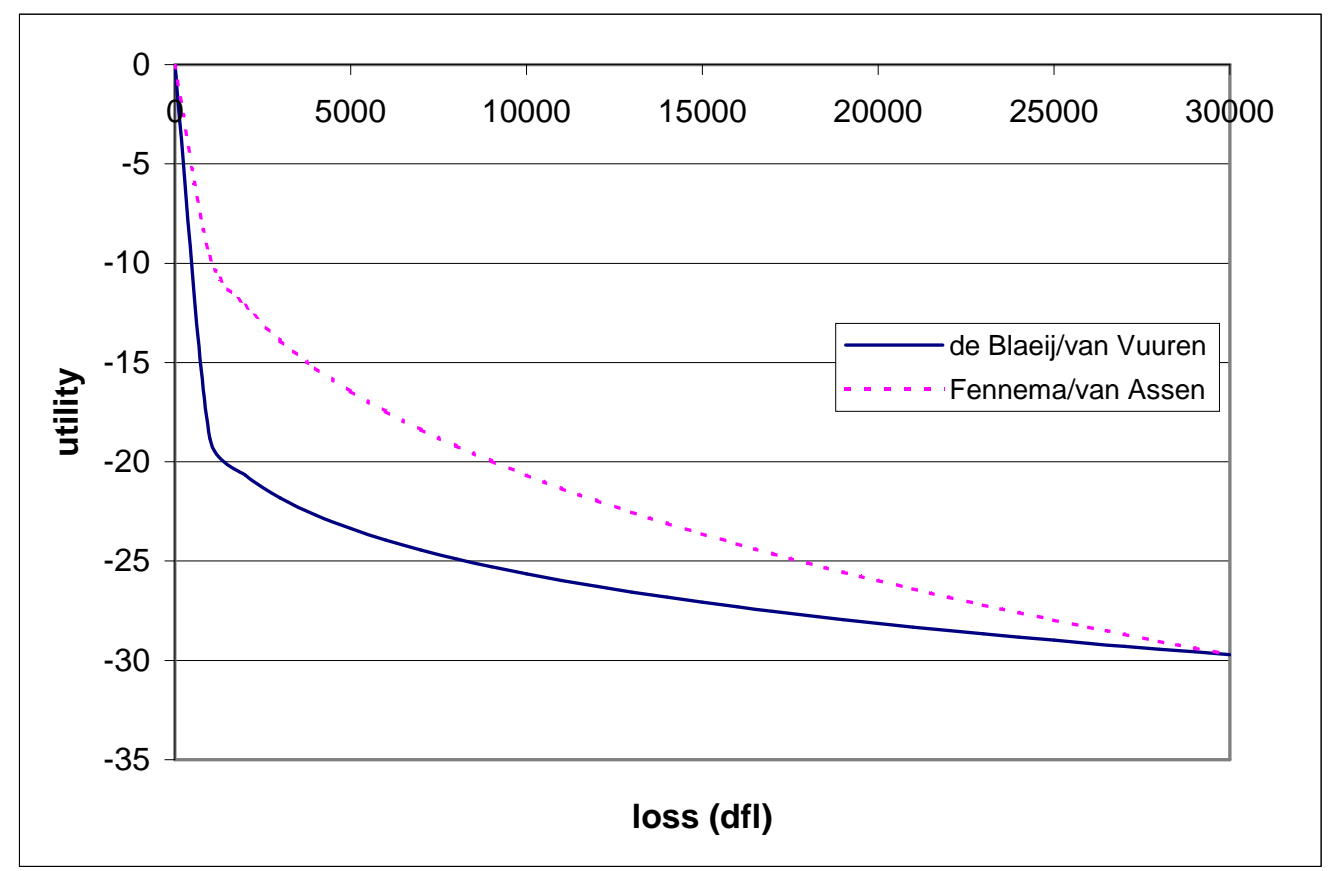

The result of the estimation of the probability weighting function was not a great success. Most people had a lot of difficulties with filling in the questionnaire. The results can be found in Table 6 . The most remarkable property of the weighting function is that it is more or less constant, or in other words, independent of the probability itself. To illustrate this, we have drawn a graph of the probability weighting function in Figure 2. Of course, each individual has her own weighting function, so we have taken the average values in this graph. The property that individuals are unable to tell apart small probabilities is seen to be independent from the utility specification. Not only the utility function that we have estimated above, but also the utility function of Fennema and van Assen (1999) and even the linear utility specification yield a constant probability weighting function. If we look at the absolute level of the probability weighting function, then it is seen that most people largely overestimate the probabilities involved. As is seen from the picture, this largely depends on the choice of utility function. In our specification the average level is about 0.4, while in the Fennema/van Assen and the linear specification it is about 0.3 and 0.1 respectively - still a large overestimation. The authors do not believe that the figure of 0.4 should at all be taken seriously in an absolute way, but instead it serves as an indication that the respondents are unable to make reasonable estimates about the risks involved. In the concluding section we will come back to this. 
Table 6. Probability weigthing functions

\begin{tabular}{c|cc|cc|cc}
\hline & \multicolumn{2}{|c|}{ de Blaeij/van Vuuren } & \multicolumn{2}{c|}{ Fennema/van Assen } & \multicolumn{2}{c}{ Linear Utility } \\
\hline $\mathrm{p}$ & $\mathrm{w}(\mathrm{p})$ & $\mathrm{w}(\mathrm{p}) / \mathrm{p}$ & $\mathrm{w}(\mathrm{p})$ & $\mathrm{w}(\mathrm{p}) / \mathrm{p}$ & $\mathrm{w}(\mathrm{p})$ & $\mathrm{w}(\mathrm{p}) / \mathrm{p}$ \\
$1: 100$ & 0.4600 & 46 & 0.2740 & 27 & 0.193 & 19 \\
$1: 500$ & 0.4882 & 244 & 0.3823 & 191 & 0.2127 & 106 \\
$1: 7500$ & 0.4592 & 3444 & 0.2837 & 2128 & 0.1353 & 1015 \\
$1: 625000$ & 0.5745 & 359093 & 0.3631 & 226924 & 0.1458 & 91126 \\
$1: 11000$ & 0.4504 & 4955 & 0.3147 & 3461 & 0.1357 & 1492 \\
$1: 10000$ & 0.4366 & 4366 & 0.3259 & 3259 & 0.1693 & 1693 \\
$1: 2500$ & 0.4016 & 1004 & 0.2762 & 691 & 0.1172 & 293 \\
$1: 900$ & 0.3244 & 292 & 0.2214 & 199 & 0.1170 & 105 \\
\hline
\end{tabular}

Figure 2. Probability weighting function

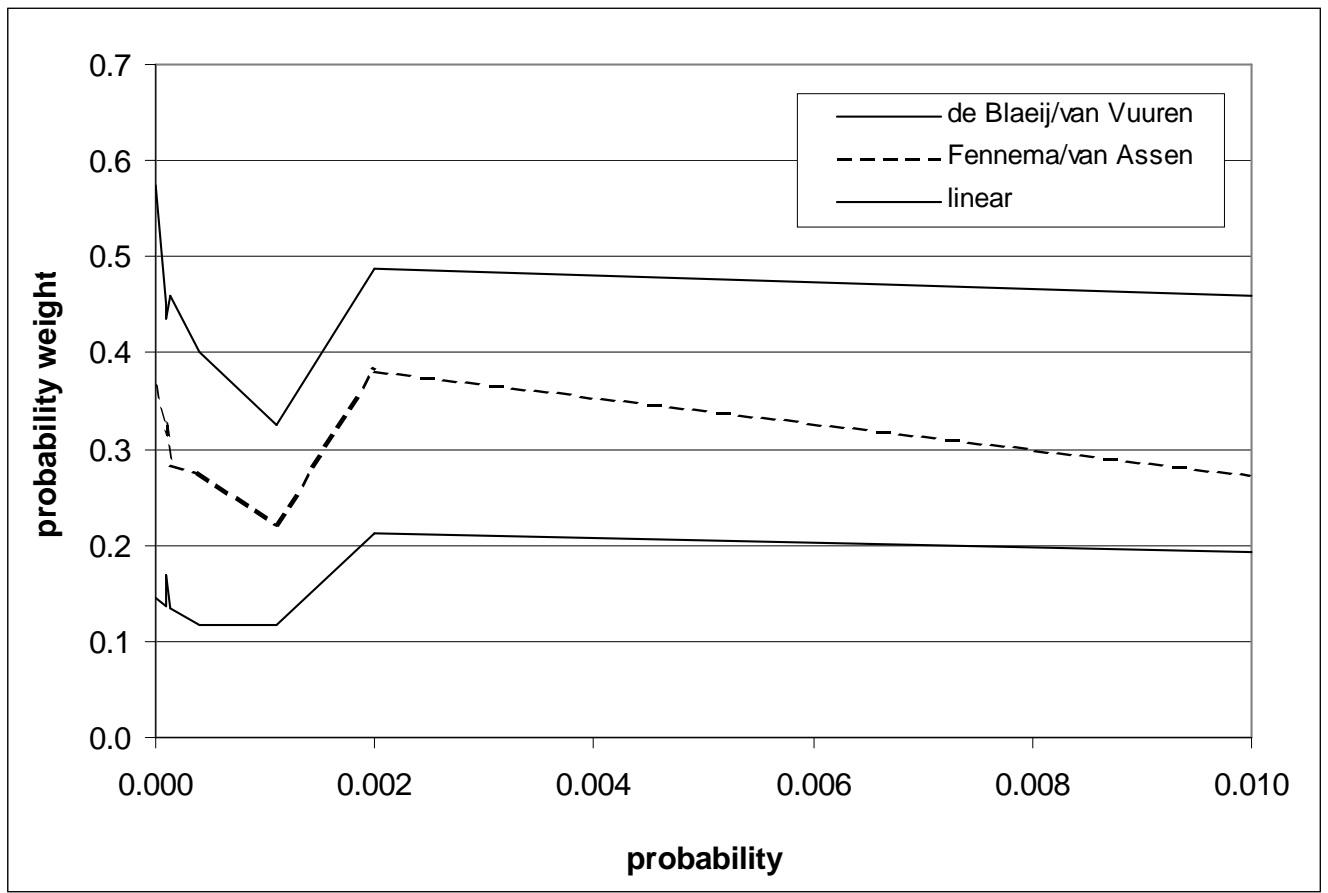


Figure 3. Probability weighting function for fatal accidents

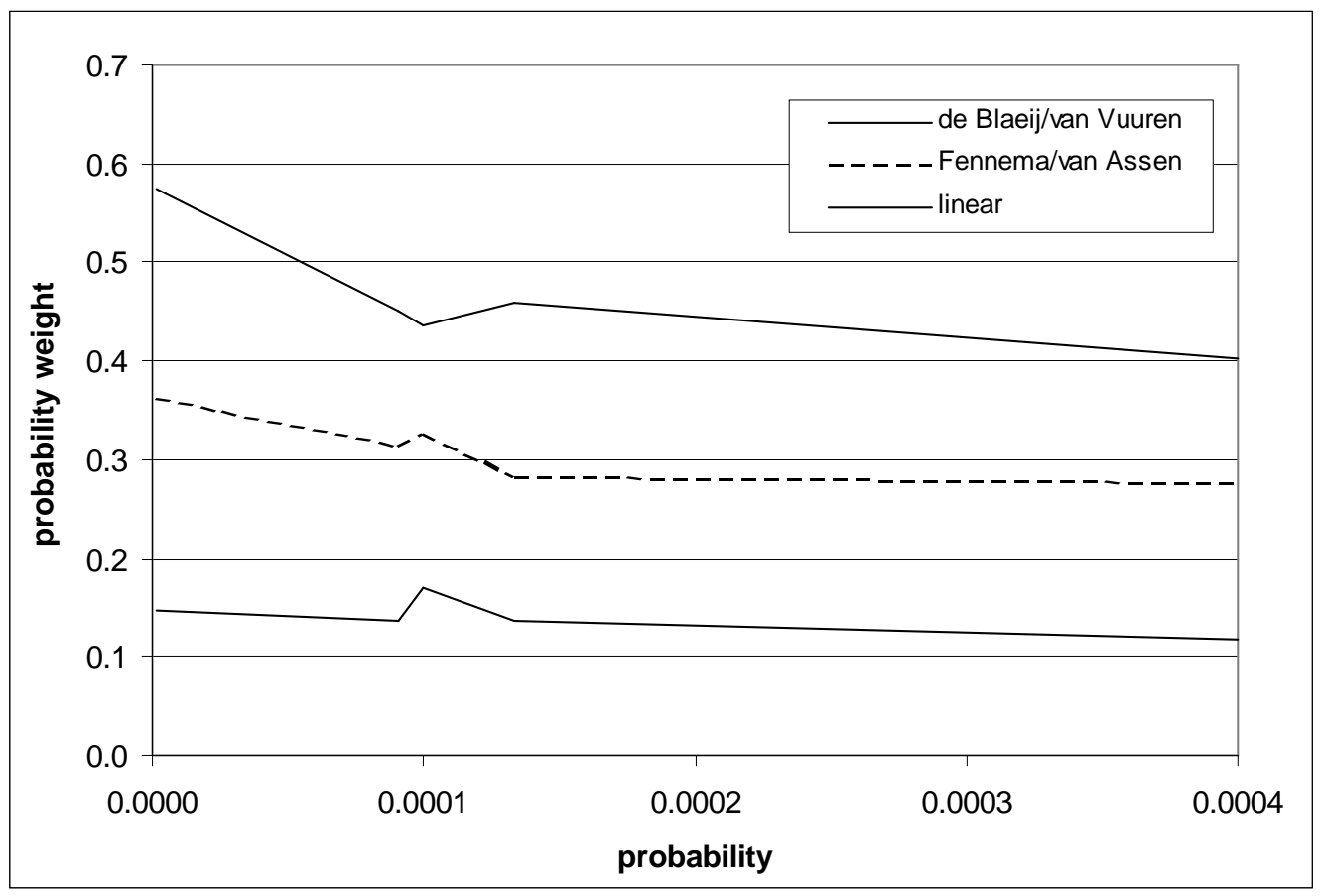

\section{Discussion and conclusion}

Although this paper has a tentative character due to the limited number of respondents in our data set, we are able to formulate some conjectures. Although these need to be tested with a more adequate data set the authors are convinced that the results obtained can serve as a guide in a possible future analysis.

It turned out that people have a median willingness to pay of Dfl 156 in order to avoid a yearly probability of $1 / 100$ on an accident that results in light injury. Within the expected utility framework this would imply a median valuation of such an accident of Dfl 15,625. It is however found that the respondents display a lot of variation in their 'tastes', which even increases for more severe accidents. The median WTP for avoiding heavy injury or fatal injury is about Dfl 1,000 and Dfl 5,000 for yearly probabilities of 1/500 and 1/7500 respectively. Thus expected utility theory implies a valuation of Dfl 500,000 for avoiding heavy injury and Dfl 37,500,000 for fatal injury. To compare this last value with earlier studies, the revealed preference method has generated values between Dfl 180,000 (Melinek, 1974) and Dfl 8,000,000 (Blomquist and Miller, 1992). Estimates obtained with the contingent valuation method are higher, between Dfl 400,000 (Jones-Lee et al., 1983) and Dfl 600,000,000 (Maier et al., 1989). About the valuation of a statistical injury, as far as we know, comparable estimates do not exist.

The study of the valuation of losses has provided us with a utility function that is concave in shape. We have found that this concavity is much more present than in earlier studies (Fennema and van Assen (1999)), but this may well be due to the large sums that were 
involved in our questionnaire: We suspect that most people have 'more concave' preferences as larger amounts of losses are involved. For example, most people would be indifferent between losing 40 million or losing 60 million, as it would imply their bankruptcy anyway.

As for the last part of the questionnaire, involving the derivation of the probability weighting function, it turned out that this was too difficult for most people. On the one hand it can be argued that the questionnaire should have been made easier. On the other hand one may argue that the decisions that have to be made in real life are not easy either. The authors have been convinced that most people simply lack intuition to estimate very small probabilities in an 'adequate fashion'.

Secondly, it seemed that individuals base their decisions on the possible outcomes of the decision tree rather than on the probabilities involved. It looks like individuals are hardly able to distinguish between probabilities that lie somewhere in the range between 0 and 1/100. It also turned out that some respondents did not fill out the questionnaire in a way that is in accordance with utility theory. Our main conjecture of this paper is therefore:

When people have to choose to participate or not to participate in a potentially risky activity with a low probability of the "bad outcome" (say $\leq 1 / 100)$, they base their decision on the possible outcomes of the activity rather than on the probabilities involved.

As said, the most likely reason for this phenomenon is that people lack intuition for interpreting small probabilities. For probabilities, which are close enough to 0.5 it is relatively easy to think of a 'frequency interpretation' of the possible outcomes. For very small (or very large) probabilities this 'frequency interpretation' may not be applicable: For example, given the reported probabilities, the probability that one will ever be involved in a bus accident (during her lifetime) equals only about 0.001 .

A policy implication of this conjecture would be that governments that want to inform their citizens about the riskiness of certain activities should rather focus on the possible outcomes of those activities instead of trying to explain what exactly are the risks of those activities in terms of probabilities and/or frequencies. This policy has already been (successfully) applied for the case of smoking behaviour.

\section{References}

M. Abdellaoui (1998), Parameter-free elicitation of utilities and probability weighting functions. Manuscript, ENS, Cachan.

W. Adamowicz, P. Boxall, M. Williams and J. Louviere (1998), Stated Preference Approaches for Measuring Passive Use Values: Choice experiments and Contingent Valuation. American Journal of Agricultural Economics 80, 64-75.

D.K. Benjamin and W.R. Dougan (1997), Individuals' estimates of the risks of death: Part I - A reassessment of the previous evidence. Journal of Risk and Uncertainty $15,115-133$. 
H. Bleichrodt and J.L. Pinto (1998), A parameter-free elicitation of the probability weighting function in medical decision analysis. Manuscript, Erasmus University, Rotterdam.

G.C. Blomquist and T.R. Miller (1992), Values of life and time implied by motorist use of protection equipment. Unpublished manuscript. Department of Economics, University of Kentucky and the Urban Institute, Washington D.C.

R. Bostic, R.J. Hernstein and R.D. Luce (1990), The effect on the preference reversal phenomenon of using choice indifferences. Journal of Economic Behavior and Organization 13, 193-212.

T. Carthy, S. Chilton, J. Covey, L. Hopkins, M. Jones-Lee, G. Loomis, N. Pidgeon, A. Spencer (1999), On the Contingent Valuation of Safety and the Safety of Contingent Valuation: Part 1- Caveat Investigator. Journal of Risk and Uncertainty 17(3), 187-213.

CBS (1998), Tijdreeksen verkeer en vervoer 1998, Den Haag.

P. Dolan, C. Gudex, P. Kind and A. Williams (1996), Valuing health states: A comparison of methods. Journal of Health Economics 15, 209-231.

P. Dolan, M. Jones-Lee and G. Loomis (1995), Risk-risk versus standard gamble procedures for measuring health state utilities. Applied Economics 27, 1103-1111.

G.R. Dowling (1986) Perceived risk: The concept and its measurement. Psychology and Marketing 3, 193-210.

H. Fennema and M. van Assen (1999), Measuring the utility of losses by means of the tradeoff method. Journal of Risk and Uncertainty 17(3), 277-295.

R. Hoevenagel (1994), The contingent valuation method: Scope and validity, Ph.D. dissertation, Vrije Universiteit, Amsterdam.

J. Jondrow, Bowes, M. and Levy, R. (1983), The optimal Speed Limit. Economic Inquiry 21, 325-336.

M.W. Jones-Lee, Hammerton, M. Abbott (1983), The Value of Transport Safety: Results of a National Sample Survey. Report to the Department of Transport. NewcastleUpon-Tyne, University of Newcastle-Upon-Tyne, Department of Economics.

M.W. Jones-Lee, G. Loomes and P.R. Philips (1995a), Valuing the Prevention of NonFatal Road Injuries: Contingent Valuation vs Standard Gambles. Oxford Economic Papers, 676-695.

M.W. Jones-Lee, G. Loomes and A. Robinson (1995b), Why did two equivalent Methods produce Two Very Different Values. In: N.G. Schwabb Criste and N.C. Soguel (eds.), "Contingent Valuation, Transport Safety and the Value of Life". Kluwer Academic, Dordrecht.

D. Kahneman and A. Tversky (1979), Prospect theory: An analysis of decision under risk. Econometrica 47, 263-291.

M.J. Koornstra, M.P.M. Matthijssen, J.A.G. Mulder, R. Roszbach and F.C.M. Wegman (1990), Naar een duurzaam veilig wegverkeer; Nationale verkeersveiligheidsverkenning 1990/2010, SWOV.

P. Lanoie, C. Pedro and R. Latour (1995), The value of a statistical life: a comparison of two approaches. Journal of Risk and Uncertainty 10, 235-257.

J. Liu and C. Hsieh (1995) Risk perception and smoking behavior: Empirical evidence from Taiwan. Journal of Risk and Uncertainty 11, 139-157. 
G. Maier, S. Gerking, P. Weiss (1989), The Economics of Traffic Accidents on Australian Roads: Risk Lovers or Policy Deficit? Empirical Australian Economic Papers 16,177-192.

S.J. Melinek (1974), A method of evaluating human life for economic purposes. Accident analysis and prevention 6, 103-114.

L.A. Morris, J.L. Swasy and M.B. Mazis (1994), Accepted risk and alcohol use during pregnancy. Journal of Consumer Research 21, 135-144.

P.M. Peeters, P. Rietveld, F.R. Bruinsma, D.J. van Vuuren and A.J. Rooijers (1998), Hoe laat denk je thuis te zijn? Rapport in opdracht van projectbureau IVVS. Peeters Advies, Vrije Universiteit Amsterdam, Centrum voor Omgevings- en Verkeerspsychologie / Rijksuniversiteit Groningen.

P. Rietveld, F.R. Bruinsma and D.J. van Vuuren (2001), Coping with unreliability in public transport chains: A case study for the Netherlands. Forthcoming in Transportation Research 35A.

N.G. Schwab Christe (1995), The valuation of human costs by the contingent method: the Swiss experience. In: Schwab Christe, N.G. and N.C. Soguel, eds., "Contingent valuation, transport safety and the value of life", Kluwer.

SWOV (1998), SWOV Interactief CD-rom, Afdeling Voorlichting en Publiciteit van de Stichting Wetenschappelijk Onderzoek Verkeersveiligheid SWOV, Leidschendam.

W.K. Viscusi, W.A. Magat and J. Huber (1990), Pricing environmental risks: Survey Assessment of Risk-Risk and Risk-Dollar Trade-Offs for Chronic Bronchitis, Journal of Environmental Economics and Management 21, 32-51.

W.K. Viscusi (1990) Do smokers underesimate risks? Journal of Political Economy 98, 1253-1269.

W.K. Viscusi (1991) Age variations in risk perceptions and smoking decisions. Review of Economics and Statistics 73, 577-588.

P. Wakker (1989), Transforming probabilities without violating stochastic dominance, In: E.E. Roskam (ed.), Ch. 1, "Mathematical Psychology in Progress", Springer, Berlin. 